\title{
Rising Imperatives*
}

\author{
Deniz Rudin \\ University of Southern California
}

\begin{abstract}
This paper provides an account of imperatives accompanied by rising intonation, formalized within the Table model. It argues that rising imperatives are conventionally weak, lacking speaker commitment.
\end{abstract}

Keywords: imperatives, intonation, speech acts, commitment

\section{Introduction}

This paper provides an account of imperatives accompanied by steeply, monotonically rising intonation (the $\mathrm{L} * \mathrm{H}-\mathrm{H} \%$ tune). I propose an account of such sentences that derives their discourse effect compositionally from the discourse effect of utterances of imperatives and the discourse effect of the $\mathrm{L}^{*} \mathrm{H}-\mathrm{H} \%$ tune. The account is formalized within an extension of the Table model (Farkas \& Bruce 2010), and makes use of an independently-motivated proposal for the meaning of the $\mathrm{L} * \mathrm{H}-\mathrm{H} \%$ tune: that it calls off speaker commitment (Truckenbrodt 2006).

The structure of this paper is as follows. $\$ 2$ presents the empirical facts; $\$ 3$ argues that rising imperatives are indeed (morpho-syntactic) imperatives; $\$ 4$ argues that the empirical facts pose problems for prior accounts of imperatives; and $\S 5$ contains the positive proposal, including the development of an extension of the Table model to utterances of imperatives.

\section{The empirical facts}

This section surveys the essential data about the behavior of rising imperatives, much of which is novel. Imperatives accompanied by the $\mathrm{L}^{*} \mathrm{H}-\mathrm{H} \%$ tune have not been widely discussed discussed in prior literature (though see Bolinger 1989;

* For helpful discussion of issues large and small, thanks to Pranav Anand, Adrian Brasoveanu, Cleo Condoravdi, Amy Rose Deal, Ashwini Deo, Donka Farkas, Sunwoo Jeong, Magda Kaufmann, Manfred Krifka, Dan Lassiter, Sven Lauer, Sophia Malamud, Jim McCloskey, Jessica Rett, Floris Roelofsen, Matthijs Westera, and audiences at Konstanz, Stanford, Irvine, Berkeley, MIT, Santa Cruz, and USC. All errors are mine alone. 
Rising imperatives

Portner 2018a; Keough, McClay, Babel \& Matthewson 2016). However, (what look like) rising imperatives are quite common in casual speech: ${ }^{1}$

(1) Buy me a drink?

(2) Let's go?

(3) Give me a ride home?

I'll return in $\S 3$ to the question of whether or not these are genuine imperatives (I'll argue that they are), but first I'd like to establish a couple of empirical facts about these apparent rising imperatives. One intuition (following Portner 2018a) is that rising imperatives sound much more tentative/suggestiony than falling imperatives.

(4) A: I really like this present grandma gave me.

a. B: Write her a thank-you note.

b. B: Write her a thank-you note?

Impressionistically speaking, in (4a) B seems to be instructing $\mathbf{A}$ to write her grandmother a thank-you note, whereas in (4b) B seems to be only pointing out a course of action relevant to A's comment. B's utterance here seems fairly similar to an utterance of You could write her a thank-you note. To put it in a slightly more theory-laden way, in (4a) B seems to have committed to the idea that that's what $\mathbf{A}$ should do, but in (4b) B seems to be leaving it up to A to decide whether that's what she should do.

I'd like to put some empirical teeth on the intuition that rising imperatives are in some sense weaker than falling imperatives. I'll do this in two ways. First, I'll discuss the possibility for the rejection of an imperative to be followed up on by $I$ insist. Then I'll move on to discuss sequences of contradictory imperatives.

\subsection{I insist}

That some imperatives feel weaker than others is an old observation-in addition to imperatives that seem to give commands or instructions, there are also imperatives that (irrespective of intonation) are felt to be more like offers, like Have a cookie (Schmerling 1982 a.o.). In this section I'll argue that rising imperatives are not the same thing as weak uses of falling imperatives. Observe the following.

1 Throughout, example sentences punctuated with a question mark are to be read as accompanied by the $\mathrm{L} * \mathrm{H}-\mathrm{H} \%$ tune (a steeply, monotonically rising intonational contour), and example sentences punctures with a period are to be read as accompanied by the $\mathrm{H}^{*} \mathrm{~L}-\mathrm{L} \%$ tune (a steeply, monotonically falling intonational contour). 
A: Have a cookie.

B: No, thanks.

A: I insist.

Even for a use of a falling imperative that is typically taken to be illocutionarily 'weak,' like an offer, the speaker can respond to the addressee's rejection of the imperative with $I$ insist. However, if the original imperative is uttered with rising intonation, following up with I insist becomes significantly degraded.
A: Have a cookie?
B: No, thanks.
A: ??I insist.

Consider also sequences in which I insist directly follows the imperative:

Have a cookie. I insist.

While 'weak' uses of falling imperatives can be insisted upon, rising imperatives cannot. This suggests that not all 'weak' imperative are created equalwhatever leads to the weakness of rising imperatives is not the same thing that leads to the weakness of 'offering' uses of falling imperatives. We might suppose that 'weak' uses of falling imperatives, like offers, are merely pragmatically weak (e.g. Farkas 2011). I will argue that rising imperatives are conventionally weak.

\subsection{Contradictory sequences}

Intonation affects whether a sequence of imperatives is contradictory or not:

(9) A: I'm having trouble managing my time lately. I don't know what my plans should be for this evening, do you have any advice?

a. B: Work on your paper? Blow it off and go to the beach?

b. B: Work on your paper. \#Blow it off and go to the beach.

Example (9) displays a crucial asymmetry. In (9b), the speaker contradicts herself, instructing the addressee to pursue mutually incompatible courses of action. ${ }^{2}$ However, as (9a) shows, a normally-contradictory sequence of imperatives can become felicitous if each imperative is accompanied by the $\mathrm{L}^{*} \mathrm{H}-\mathrm{H} \%$ tune. In other words, rising intonation is able to render a sequence of ordinarily-contradictory imperatives non-contradictory. I will argue that this is explained by the conventional weakness of rising imperatives.

2 Note again that the sentence-final period in these examples should be taken as signifying that the utterance is accompanied by a steep, monotonic fall (the $\mathrm{H}^{*} \mathrm{~L}-\mathrm{L} \%$ tune). There are non-monotonically falling tunes that nonetheless end in a final fall with which examples like this can be made felicitous. 
Rising imperatives

\section{Rising imperatives are imperatives}

In English, imperatives are morphologically indistinguishable from infinitive VPs. ${ }^{3}$ Because English has no special imperative verbforms, it is difficult to prove conclusively that a given sentence is a (morphosyntactic) imperative. In this section, I argue that the phenomena at issue are indeed best analyzed as rising imperatives. I argue that apparent rising imperatives in English cannot be reduced to either of the non-imperative sentence types they most resemble: fragment answers, or questions that have undergone left-edge ellipsis.

\subsection{Rising imperatives vs fragment answers}

One potential analysis of some apparent rising imperatives in English is that they are fragment answers (Merchant 2004; Stainton 2005). This analysis could be applied to data in which an apparent rising imperative is used to reply to a question:

(10) A: What should I read tonight?

B: A novel?

(11) A: What should I do tonight?

B: Read a novel?

In (10), A's question seeks an answer that can be provided by a DP, and a DP fragment is an appropriate response. Likewise, in (11), A's question seeks an answer that can be provided by a VP, and a VP fragment is an appropriate response. Why should we think that B's response in (11) is anything other than B's response in (10): a fragment answer? If apparent rising imperatives in English are just fragment VPs, then accounting for them reduces to accounting for rising intonation on fragment answers.

There are empirical ways that we can tell fragment answers apart from imperatives. Negation in imperatives behaves in a particular way:

a. Don't text him back anymore.

b. * Not text him back anymore.

Negated imperatives require contraction with $d o$; bare negation is never allowed. But both kinds of negation are fine in fragment answers:

3 In some cases, English imperatives have more going on than infinitive VPs-for instance negated imperatives, in which do-support occurs (1), and imperatives with overt subjects (2):

(i) Don't stay out too late.

(ii) Everyone be quiet.

However, even in these cases, the verb shows up in its infinitive form. 
(13) A: I keep telling the guy who I broke up with that I'm not interested in talking to him, but he won't stop texting me. What should I do?

a. B: Don't text him back anymore?

b. B: Not text him back anymore?

In this case, A's question licenses fragment answers of the appropriate size; we can tell that that (13b) is a fragment answer, because it's not a possible imperative. So we might assume that (13a) is a fragment answer as well, since (13b) demonstrates that the question licenses fragment answers of the appropriate size.

The grammaticality of (13b) is a test for whether the context that licenses fragments of the relevant kind. If imperative-sized fragment answers are possible, (13b) should be appropriate. Not all questions license imperative-sized fragment answers, and if we alter the context so that it no longer licenses fragment answers, rising imperatives are still possible:

(14) A: I keep telling the guy who I broke up with that I'm not interested in talking to him, but he won't stop texting me. Do you have any advice?

a. B: Don't text him back anymore?

b. B: *Not text him back anymore?

Rising imperatives are possible in contexts where imperative-sized fragment answers aren't. Therefore, apparent rising imperatives in English can't be reduced to fragment answers. The upshot: when an apparent rising imperative is given in response to a question, we must control the question to make sure that it doesn't license imperative-sized fragment answers. I've done so throughout this paper.

\subsection{Rising imperatives vs left-edge ellipsis}

Apparent rising imperatives in English resemble questions that have undergone ellipsis at their left edge (Zwicky \& Pullum 1983; Fitzpatrick 2006; Weir 2012). Consider the following examples, due to Fitzpatrick (2006):

(15) < Does> anybody want a hot dog?

(16) <Has $>$ anyone seen John today?

(17) <Is > anybody going to the game?

(18) $<$ Đ $\ominus>$ you want chicken or beef?

I'll call these instances of 'left-edge ellipsis,' following Weir (2016). Many apparent rising imperatives in English admit of intuitively plausible paraphrases with questions: 
Rising imperatives

(19) Buy me a drink? $\approx$ Do you want to buy me a drink?

We might think, then, that some apparent rising imperatives are derived from questions via left-edge ellipsis, like so:

$<$ Do you want to $>$ buy me a drink?

Such an account would need to explain why so much more is elided here than in normal cases of left-edge ellipsis, which as seen above and below generally elide only something very small, like an auxiliary and/or a pronominal subject. I argue that irrespective of this concern, a left-edge ellipsis account of apparent rising imperatives in English is not tenable. I'll give two arguments.

First, left-edge ellipsis is prosodically licensed, and is only possible at the left edge of an intonational phrase. The following examples come from Weir (2016).

(21) a. (Have you) seen the new Star Wars?

b. I'm asking you whether *(you have) seen the new Star Wars.

a. (I) won't bother seeing it, I think.

b. I think *(I) won't bother seeing it.

Rising imperatives do not display this pattern. Material is allowed to intervene between the 'missing' subject and the left edge of an intonational phrase:

(23) A: I'm having trouble managing my time lately. I don't know what my plans should be for this evening, do you have any advice?

B: Maybe work on your paper?

My second argument that apparent rising imperatives cannot be reduced to cases of left-edge ellipsis is that it's difficult to see how an ellipsis account could deal with negated rising imperatives:

(24) Don't text him back anymore?

It is difficult indeed to see how this could be derived via left-edge ellipsis from a question. Don't should be sitting in C, to the left of the putatively elided subject. As left-edge ellipsis is a process that gets rid of material on the left edge of the sentence, there is no way to left-edge elide the subject without also eliding don't.

\section{Problems for prior accounts}

In this section, I discuss the ramifications of the empirical observations above for various prior proposals for the semantics of imperatives. I show that accounting for rising imperatives is a non-trivial problem for prior accounts. ${ }^{4}$

4 In $\S 5$, I attempt to derive the behavior of rising imperatives from a previously proposed account of the contribution of the $\mathrm{L}^{*} \mathrm{H}-\mathrm{H} \%$ tune to the meaning of utterances of declarative sentences 


\subsection{Portner (2018a)}

Portner (2018a) provides the only formal account of rising imperatives of which I am aware. Portner builds an extension of the 'to-do list' system in Portner 2004 (inspired by Gunlogson 2001 and Farkas \& Bruce 2010) in which each interlocutor has their own individual copy of each other's to-do lists. When a falling imperative is uttered, the speaker adds the property it denotes to their own version of the addressee's to-do list thereby, and simultaneously proposes that the addressee add it to their own version of their to-do list as well, which would give rise to a shared understanding among the interlocutors that the addressee is to take action to make the indicated property true of themself. A rising imperative adds a property to the $a d$ dressee's version of the addressee's to-do list, while making the same proposal that the interlocutors come to a shared understanding of the content of the addressee's to-do list.

Portner describes the effects his theory predicts for falling and rising imperatives like so: In uttering a falling imperative, the speaker communicates that she "rates futures in which the addressee [obeys the imperative] higher than those in which he does not, and creates an expectation that this judgment will become mutual" (1b). In uttering a rising imperative, the speaker communicates that she "thinks the addressee rates futures in which the addressee [obeys the imperative] higher than those in which he does not, and creates an expectation that this judgment will become mutual" (2b). To paraphrase extremely simply: on Portner's view, a falling imperative indicates that the speaker wants the addressee to act in a certain way, and a rising imperative indicates that the speaker thinks the addressee wants to act in a certain way. In both cases, the speaker intends to create a common understanding that for the addressee to act in that way would be preferable.

I believe Portner's proposal to be unable to capture the empirical facts discussed above irrespective of whether or not one shares the intuition that rising imperatives signal the speaker's expectations of what the addressee wants to do. Portner's account is incapable of capturing the crucial asymmetry in (9): that sequences of imperatives that are contradictory with steep, monotonic falls become felicitous with steep, monotonic rises.

On Portner's view, a sequence of falling imperatives and a sequence of rising imperatives do the same thing, formally speaking: they perform a sequence of updates to a to-do list, adding multiple properties to it one after another. The only difference, for Portner, is whether the to-do list being updated is the speaker's ver-

(Truckenbrodt 2006; Rudin 2018). As such, I will restrict my comments to theories that provide an explicit account of rising imperatives, or that treat imperatives as updating the discourse context in the same way that declaratives sentences do. Other theories (e.g. Charlow 2014 and Starr 2017) go undiscussed for reasons of space. 
Rising imperatives

sion or the addressee's version. As the contradictoriness of the sequence of falling imperatives in (9) shows us, some sequences of updates to a to-do list are incoherent: a coherent to-do list cannot contain two properties that cannot both be made true of the holder of the to-do list. It shouldn't matter whether the to-do list is the speaker's version or the addressee's version: in the falling imperative sequence, on Portner's view, the speaker has expressed contradictory preferences about what course of action the addressee should take, and created the expectation that those contradictory preferences will become shared preferences. In the rising imperative sequence, something nearly identical has happened: the speaker has expressed contradictory expectations about what the addressee's preferences are, and again created the expectation that those contradictory preferences will become shared preferences. On any view in which rising imperatives comprise to-do list updates, sequences of mutually incompatible rising imperatives should be infelicitous for the same reason sequences of mutually incompatible falling imperatives are; the facts show just the opposite.

\subsection{Kaufmann (2012a, 2016)}

On Kaufmann's account, imperatives contain a covert strong priority modal, and are identical to declarative priority modalized sentences except that the covert modal carries a presupposition that ensures that it is interpreted performatively. In other words, on Kaufmann's view:

(25) 【Go to the store $\rrbracket \approx \llbracket$ I hereby decree that you must go to the store $\rrbracket$

However, rising imperatives clearly are not the same as performatively-interpreted must-claims: they do not create obligations in the same way as falling imperatives. So at the very least, if Kaufmann's theory is to be able to deal with rising imperatives, it must be that rising intonation somehow calls off the relevant presuppositions. Let's assume for a moment that this is so. Even if there were a mechanism that called off Kaufmann's presuppositions, we'd still be left with the core semantics of her proposal: a covert strong priority modal. But declarative sentences with overt strong priority modals, which should have the same semantics as a presuppositioncancelled imperative on Kaufmann's account, simply do not interact with rising intonation in the same way that imperatives do:

(26) a. Work on your paper? Blow it off and go to the beach?

b. \#You \{must, have to, need to $\}$ work on your paper? You \{must, have to, need to blow it off and go to the beach?

One might retreat slightly, and say that imperatives contain covert weak necessity modals, like should, not strong necessity modals, like must (see Kaufmann 
$2012 \mathrm{~b}$ for arguments both for and against treating imperative modality as weak necessity). However, the paraphrase is still not right:

a. Work on your paper? Blow it off and go to the beach?

b. ??You should work on your paper? You should blow it off and go to the beach?

It's clear that (27b) does not mean the same thing as (27a). The former asks the addressee to entertain the possibility that what they should do is work on their paper and the possibility that what they should do is blow it off and go to the beach. The latter asks the addressee to consider that they could work on their paper, and that they could blow it off and go to the beach.

That Kaufmann's proposal reduces the meaning of imperatives to the meaning of a particular use of modalized declaratives is a design feature of her account-she takes it to be desirable for imperatives to be of the same semantic type as declaratives, and to interact with the same contextual components in the same ways. However, the declarative paraphrases that seem sensible for canonical uses of imperatives do not interact with rising intonation in the same way that the actual imperatives do, suggesting that Kaufmann's story is not the full story.

\subsection{Condoravdi \& Lauer $(2012,2017)$}

Condoravdi \& Lauer's account also has the property that imperative sentences are of the same semantic type as declarative sentences, and interact with the context in the same way. Condoravdi \& Lauer (2017) take imperatives to denote the proposition $p$ that the speaker has a public effective preference for some proposition $q$. An effective preference is a preference that is used for rational action choice, and as such is subject to requirements of consistency and realism. ${ }^{5}$

Because Condoravdi \& Lauer give an account of imperatives in which they interact with the context in the same way as declaratives, we might expect imperatives to interact with intonation in the same way as their declarative paraphrases. On Condoravdi \& Lauer's account, imperatives are speaker preferential attitudes of a particular kind:

【Leave $\rrbracket \approx$ II want you to leave $\rrbracket$

Where want is interpreted in terms of effective preferences

But again, what we see empirically is that overt speaker preferential attitudes don't interact with intonation in the same way that imperatives do:

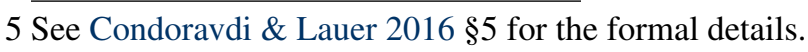


Rising imperatives

(29) a. Work on your paper? Blow it off and go to the beach?

b. \#I want you to work on your paper? I want you to blow it off and go to the beach?

That overt speaker preferential attitudes do not interact with intonation in a way that is congruent with imperatives is problematic for the idea that imperatives simply denote speaker preferential attitudes, and otherwise interact with the context in the same way that speaker preferential attitudes do.

\section{Proposal}

I'll give an account of rising imperatives that seeks to explain their behavior compositionally, in terms of the contribution of the imperative clause type to the meaning of an utterance, and the contribution of the $\mathrm{L}^{*} \mathrm{H}-\mathrm{H} \%$ tune. I assume, building on prior work, that $\mathrm{L}^{*} \mathrm{H}-\mathrm{H} \%$ signals that the speaker is making no discourse commitments by virtue of their utterance (Truckenbrodt 2006), and I follow Rudin (2018) in formalizing that analysis within the Table model (Farkas \& Bruce 2010), which allows for a particularly explicit account of how two discourse moves can differ only in terms of speaker commitment. I'll briefly give background on the Table model in $\$ 5.1$, and extend that model to imperatives in $\$ 5.2$. In $\$ 5.3$, I give a pragmatics for rising imperatives, and in $\S 5.4$ and $\S 5.5 \mathrm{I}$ show how the proposal accounts for the data.

\subsection{Background: Farkas \& Bruce (2010)}

Farkas \& Bruce's Table model is in effect an elaboration of Stalnaker (1978), which models how assertions are used to build Common Ground. The Table model introduces a proposal step to assertions, in which a speaker takes on a public discourse commitment and projects a future Common Ground. ${ }^{6}$ The model has the following five components:

(30) BASic Components of The Farkas \& Bruce (2010) Model:

a. COMmon GRound $(C G)$

The set of all propositions that all discourse participants are publicly committed to

b. Context Set $(C S)$

The set of all worlds that are compatible with all propositions in the Common Ground $(=\cap C G)$

6 This model also provides a unified account of responses to assertions and questions; I ignore this aspect of the proposal here. 


\section{c. Discourse COMMiTMENTS}

For all discourse participants $X$, there is a set $D C_{X}$ of propositions $X$ has publicly committed to

d. The TABLe $(T)$

A push-down stack of Issues (sets of propositions), the uppermost element of which $(\operatorname{MAX}(T))$ is currently at issue

e. Projected Set $(P S)$

The set of all Common Grounds that could result by adding an element of $\operatorname{MAX}(T)$ to the current $C G$

I assume that in addition to these components, a discourse context contains a set $A$ of discourse participants, and a Question Under Discussion (QUD). ${ }^{7}$

\section{Discourse ConTEXTS}

A context $c_{n}$ is a tuple $\left\langle A_{n}, D C_{n}, T_{n}, C G_{n}, C S_{n}, P S_{n}, Q U D_{n}\right\rangle$

Where $A_{n}$ is a set of individuals,

$D C_{n}$ is a set of sets of discourse commitments $D C_{a, n}$, one for each $a \in A_{n}$

$T_{n}$ is a Table,

$C G_{n}, C S_{n}$, and $P S_{n}$ are a Common Ground, a Context Set, and a Projected Set, such that $C S_{n}=\cap C G_{n}$ and $P S_{n}=\left\{C G_{n}+p: p \in \operatorname{MAX}(T)\right\}$,

and $Q U D_{n}$ is a contextually salient question

An assertion of a sentence denoting a proposition $p$ is a function of the following form:

$$
\begin{aligned}
& \text { ASSERT }\left(s, s p, c_{n}\right) \rightarrow c_{n+1} \text {, such that } \quad \text { (cf. Farkas \& Bruce's ex. 9) } \\
& \text { i. } D C_{s p, n+1}=D C_{s p, n}+p \\
& \text { ii. } T_{n+1}=T_{n}+\{p\} \\
& \text { iii. } P S_{n+1}=\left\{C G_{n+1}+p\right\} \\
& \text { iv. in all other respects, } c_{n+1}=c_{n}
\end{aligned}
$$

The speaker makes a discourse commitment to $p$, and the Issue $\{p\}$ is placed on the Table, making $p$ at issue and projecting a Common Ground including $p$.

All components of the Table model are modally unified: they are to be interpreted DOXASTICALLY. A speaker's discourse commitments are propositions that they are presenting themselves as though they believe. The Common Ground is a set of propositions that all interlocutors are doxastically committed to for the purposes of the conversation. The propositions in the maximal element of the Table are

7 Farkas \& Bruce (2010) intend the Table to serve the purpose of the QUD as developed by Roberts (1996), but also intend it to legislate what content is currently at issue, and to provide antecedents for elliptical response particles. For an argument that those purposes should be kept separate from the QUD see Rudin (2018) §1.2.4. 
Rising imperatives

those propositions currently under consideration as potential mutual doxastic commitments, and the Projected Set shows what it would look like if those potential mutual doxastic commitments were made. Finally, the QUD structures doxasticallyoriented inquiry: which of these propositions should we believe is true ${ }^{8}$

\subsection{Extending the model to imperatives}

I propose a programmatic extension of the Table model that bifurcates it into doxastic and teleological halves, identical to each other except in terms of the modal interpretation of their components. The doxastic half of the model is identical to the standard Table model. I propose that utterances of imperatives do exactly the same thing that standard assertions do, except that they interact with the teleological half of the model, not the doxastic half. ${ }^{9}$ For the sake of concreteness I will assume, following Condoravdi \& Lauer (2012), that the modality relevant to the teleological half of the context is effective preferences. ${ }^{10}$

DisCOURSE COMMITMENTS (bifurcated version):

For all discourse participants $X, D C_{X}=\left\langle D C_{d o x, X}, D C_{t e l, X}\right\rangle$

Where $D C_{d o x, X}$ is a set of propositions that $X$ is publicly committed to acting as though she believes,

and $D C_{t e l, X}$ is a set of propositions that $X$ is publicly committed to acting as though she has an effective preference for

Teleological Discourse Commitments $\left(D C_{t e l}\right)$ correspond to Condoravdi \& Lauer's (2012, 2017) Public Effective Preferences. Effective preferences are used to guide action choice, so they are required to be consistent and realistic. The consistency requirement, simply stated, is that the grand intersection of any agent's $D C_{t e l}$ must not be the empty set. We could state the condition on realism like so:

$$
\begin{aligned}
& \text { REALISM CONDITION ON } D C_{t e l} \text { : } \\
& \text { For any agent } X,\left[\forall p: p \in D C_{t e l, X}\right] p \cap \cap D C_{d o x, X} \neq \varnothing
\end{aligned}
$$

An agent's doxastic commitments constrain their possible teleological commitments.

8 Note that I gloss over, here and throughout, the difference between doxastic and epistemic modality. The difference is not of crucial importance to the phenomena that I discuss; if you have a stake in whether asserting and questioning involve knowledge or just belief (e.g. Williamson 2000), feel free to replace doxastic with epistemic as you make your way through the main text.

9 For a different implementation, making use of Portner's (2004) to-do lists, see Farkas (2011).

10 One could imagine an alternative implementation in which the relevant modality is priority modality of the kind made use of by Portner (2007) and Kaufmann (2012a). I will not attempt here to weigh the relative merits of such an implementation to the one developed in the main text. 
COMMON GROUND (bifurcated version):

$C G=\left\langle C G_{d o x}, C G_{t e l}\right\rangle$

Where $C G_{d o x}=\left\{p: \forall X, p \in D C_{d o x, X}\right\}$, and $C G_{t e l}=\left\{p: \forall X, p \in D C_{t e l, X}\right\}$

The Teleological Common Ground $\left(C G_{t e l}\right)$ is the set of all propositions that all interlocutors are publicly committed to having an effective preference for.

CONTEXT SET (bifurcated version):

$C S=\left\langle C S_{d o x}, C S_{t e l}\right\rangle$

Where $C S_{d o x}=\cap C G_{d o x}$, and $C S_{\text {tel }}=\cap C G_{t e l} \cap C S_{d o x}$

The Teleological Context Set $\left(C S_{t e l}\right)$ is the set of all worlds compatible with all the propositions in both Common Grounds. This enforces the realism condition on effective preferences: the propositions that enter the doxastic Common Ground constrain which propositions can enter the teleological Common Ground.

THE TABLE (bifurcated version):

$T=\left\langle T_{d o x}, T_{\text {tel }}\right\rangle$

Where the maximal element of $T_{d o x}$ represents the propositions that are currently candidates for becoming members of $C G_{d o x}$,

and the maximal element of $T_{t e l}$ represents the propositions that are currently candidates for becoming members of $C G_{t e l}$

The Teleological Table $\left(T_{t e l}\right)$ hosts content under consideration for incorporation into $C G_{t e l}$. Each Table is associated with its own Projected Set, which contains possible future Common Grounds incorporating the material on it.

(38) The PRojected Set (bifurcated version):

$P S=\left\langle P S_{d o x}, P S_{\text {tel }}\right\rangle$

Where $P S_{d o x}=\left\{C G_{d o x}+p: p \in \operatorname{MAX}\left(T_{d o x}\right)\right\}$, and $P S_{\text {tel }}=\left\{C G_{t e l}+p: p \in \operatorname{MAX}\left(T_{t e l}\right)\right\}$

The Teleological Projected Set $\left(P S_{t e l}\right)$ contains a set of possible future $C G_{t e l} \mathrm{~S}$, one incorporating each element of the $\operatorname{MAx}\left(T_{t e l}\right)$.

(39) THE QUD (bifurcated version):

$Q U D=\left\langle Q U D_{d o x}, Q U D_{t e l}\right\rangle$

Where $Q U D_{d o x}$ and $Q U D_{t e l}$ are sets of propositions.

$Q U D_{t e l}$ is a question about what our effective preferences should be. I assume that $Q U D_{\text {tel }}$ plays the role Kaufmann (2016) assigns to a contextually salient deci- 
Rising imperatives

sion problem: imperatives implicitly address a decision problem, just like declaratives implicitly address a question about what the world is like. I assume that $Q U D_{t e l}$ is constrained by a realism condition as well: ${ }^{11}$

$$
\begin{aligned}
& \text { REALISM CONDITION ON } Q U D_{t e l} \text { : } \\
& {\left[\forall p: p \in Q U D_{t e l}\right] p \cap C S_{d o x} \neq \varnothing}
\end{aligned}
$$

A decision problem can only be solved by adopting an effective preference for something that we don't already know to be impossible.

I assume, following Condoravdi \& Lauer (2012; 2017) and Kaufmann (2012a; 2016), that imperatives contain a proposition-denoting sentence radical that is the argument to a left-peripheral IMP operator. Both authors take that operator to supply modal semantics. I instead take it to dictate which half of the context that proposition is used to update; the modality of imperatives comes from the modality of that half of the context, just as the doxastic interpretation of declaratives comes from the way assertions interact with the doxastic half of the context.

(41) Let $k$ be the type of a context.

$$
\llbracket \mathrm{IMP} \rrbracket=\lambda p_{s t} \cdot \lambda s p_{e} \cdot \lambda c_{k} \cdot\left[\begin{array}{lll}
D C_{t e l, s p} & = & D C_{t e l, s p, c}+p \\
T_{t e l} & =T_{t e l, c}+\{p\} \\
P S_{t e l}= & \left.C G_{t e l}+p\right\} \\
c^{\prime}=c \text { in all other respects }
\end{array}\right]^{c^{\prime}}
$$

An imperative performs the same context update as an assertion, only with respect to the teleological half of the context.

Finally, following Truckenbrodt (2006) and Rudin (2018), the L* H-H\% tune (steeply, monotonically rising intonation) applies to a function from contexts to contexts and overrides speaker commitment:

Let $K$ be an abbreviation for type $e k k$ (a function from contexts to contexts).

$$
\llbracket \mathrm{L} * \mathrm{H}-\mathrm{H} \% \rrbracket=\lambda K_{K} \cdot \lambda s p_{e} \cdot \lambda c_{k} \cdot\left[\begin{array}{l}
D C_{s p}=D C_{s p, c} \\
c^{\prime}=K(s p, c) \text { in all other respects }
\end{array}\right]^{c^{\prime}}
$$

I assume the following compositional structure:

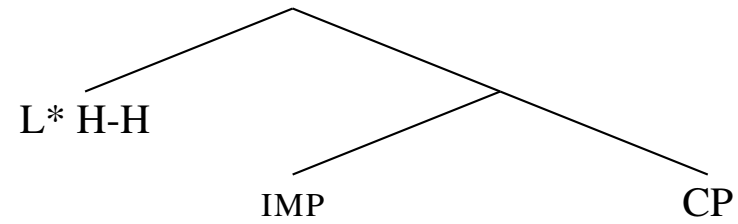

11 Cf. Kaufmann (2016) on the 'choosability' condition applied to decision problems. 
Schematically, an utterance of a rising imperative carries out the following discourse move:

UPDATE WITH A RISING IMPERATIVE

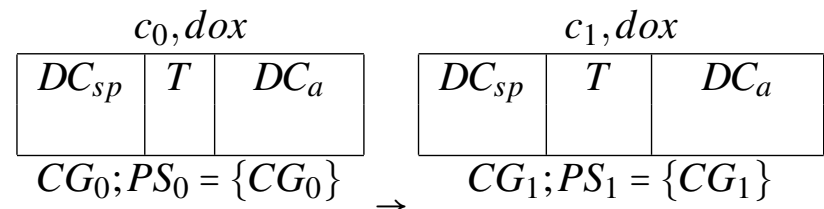

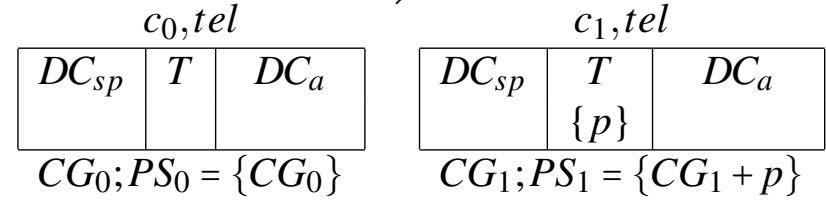

In the teleological half of the context, the utterance raises an Issue containing the proposition denoted by the imperative's sentence radical, and the projected set is altered thereby; the context is otherwise unchanged.

\subsection{Rising imperatives: the basic pragmatics}

I will now make some Gricean assumptions about the pragmatics of utterances of imperatives. First, I assume the following generalization of Roberts's (1996) notion of the maxim of RELATION:

(45) Relation:

For any modality $\alpha$, a discourse move $m$ that places $P$ on $T_{\alpha}$ is relevant iff adding an element of $P$ to $C G_{\alpha}$ would (partially) answer $Q U D_{\alpha}$

An utterance of a rising imperative is cooperative only if $p$ could resolve the contextually salient decision problem.

I will make the following assumptions about the application of the maxims of QUALITY and QUANTITY as they apply to making teleological commitments:

QUALITY (teleological commitment version):

1) Do not add a proposition to $D C_{t e l}$ if it is incompatible with the maximal elements of your private effective preference structure.

2) Do not add a proposition to $D C_{t e l}$ if it is not a maximal element of your private effective preference structure.

QUANTITY (teleological commitment version):

The more commitments you can make, the better, as long as doing so violates no other maxims. 
Rising imperatives

The maxim of QUALITY is a straightforward extension of the maxim as it is normally applied to doxastic commitments: its first clause enforces that the commitments one makes are not outright incompatible with one's actual internal state (here preferences instead of beliefs), and its second clause enforces that the commitments one makes are indeed entailed by it. QUANTITY, as always, says that more is better, ceteris paribus.

I assume that rising imperatives are in pragmatic competition with falling imperatives. As the two constructions differ only with respect to whether the speaker incurs a teleological commitment to $p$, on the basis of QUANTITY a falling imperative is always to be preferred to the corresponding rising imperative unless making that commitment would be uncooperative for other reasons. There is no distinction between the two constructions with respect to RELATION, as they place the same content on the Table. So when a speaker utters a rising imperative denoting $p$, we can infer that for the speaker to have committed to $p$ would have violated QUALITY. ${ }^{12}$

But would the speaker's commitment to $p$ have violated QUALITY 1 or QUALITY 2? That is to say, should we infer that the speaker has effective preferences that are incompatible with $p$, or simply that the speaker lacks an effective preference for $p$ at present? The pragmatics of the projected set gives us an answer.

QUALITY (teleological projection version):

1) Do not add a hypothetical Common Ground to the projected set if an interlocutor has made a public commitment that is incompatible with that Common Ground (i.e.: don't project $C G_{t e l}+p$ if there is some interlocutor $A$ such that $\left.\cap D C_{t e l, A} \cap p=\varnothing\right)$

2) Do not add a hypothetical Common Ground to the projected set if you have reason to believe there is an interlocutor whose private effective preferences are incompatible with that Common Ground (i.e.: don't project $C G_{t e l}+p$ if you have reason to believe there is an interlocutor whose private effective preferences entail $\neg p$ )

In short, it is not cooperative to project a $C G$ that you have reason to believe could not actually come about.

Though they make no commitments, the speaker's utterance leads to a projected set containing $C G_{t e l}+p$, which is only cooperative if they have no reason to believe that any interlocutor's effective preferences are incompatible with $p$. As they themselves are an interlocutor, we can safely infer that their effective preferences are not incompatible with $p$, and therefore that for them to have committed to $p$ would've violated only QUALITY 2, not QUALITY 1. In other words, the utterance of a rising

12 I assume here that rising and falling imperatives are equivalently mannerly-neither is obviously more obscure, ambiguous, prolix, or disorderly than the other. 
imperative is cooperative only if the speaker's effective preferences neither entail nor are incompatible with $p$. This, in addition to the inference that $p$ would solve the contextually salient decision problem, comprises the basic pragmatics of utterances of rising imperatives.

\subsection{Accounting for contradictory sequences}

As we saw above, sequences of imperatives that are infelicitous with falling intonation can become felicitous when accompanied by rising intonation. The relevant example is repeated here:

(49) A: I'm having trouble managing my time lately. I don't know what my plans should be for this evening, do you have any advice?

a. B: Work on your paper? Blow it off and go to the beach?

b. B: Work on your paper. \#Blow it off and go to the beach.

The proposal for the discourse effect of falling imperatives correctly predicts that (49b) will be contradictory. Assume that in the context above Work on your paper denotes the proposition that the speaker spends her evening working on her paper, and that Blow it off and go to the beach denotes the proposition that the speaker doesn't work on her paper, and goes to the beach instead. These propositions are obviously disjoint. If the speaker adds two disjoint propositions $p$ and $q$ to her Teleological Discourse Commitments, then the set of worlds compatible with all of her teleological commitments $\left(\cap D C_{t e l, s p}\right)$ will be the empty set; in (49b), the speaker has made incompatible commitments.

The proposal also correctly predicts that (49a) will be fine: the speaker has made no commitments of any kind, and therefore cannot have made incompatible ones. The speaker has communicated that either $p$ or $q$ would resolve the contextually salient decision problem, and that both are compatible with but not entailed by her effective preferences.

\subsection{Accounting for $I$ insist}

As we saw in $\$ 2.1$, even weak uses of falling imperatives allow the speaker to felicitously reply to a negative response with I insist, but such responses are infelicitous with rising imperatives. I repeat the crucial data here:

(50) Have a cookie. I insist.

(51) \#Have a cookie? I insist.

I assume that $I$ insist has an elided complement, i.e. that we should read the above as I insist <that you have a cookie>. I assume that the at-issue content of $x$ 
Rising imperatives

insist that $p$ is that a relation of insistence holds between $x$ and $p\left(\right.$ insist $\left.^{\prime}(x, p)\right)$, and, furthermore, that $\operatorname{insist}^{\prime}(x, p)$ asymmetrically entails that $x$ is publicly committed to $p$. Finally, I assume that the clause type of the complement of insist determines what kind of commitment is entailed-if the complement of insist is a subjunctive clause, then $\operatorname{insist}^{\prime}(x, p)$ asymmetrically entails that $p \in D C_{t e l, x} .{ }^{13}$

The infelicity of (51) follows from the pragmatics of rising imperatives. As discussed above, in order for a rising imperative to be cooperative, it must be uncooperative for the speaker to commit to $p$. I insist, however, entails that the speaker is committed to $p$. In any situation in which I insist <that you have a cookie> is felicitous, therefore, Have a cookie? is infelicitous; it is not possible for both utterances to be cooperative relative to the same effective preference structure, as such a structure would be required to both entail and not entail $p$. In other words, the infelicitous of $I$ insist with rising imperatives follows from the proposed conventional weakness of rising imperatives: their lack of speaker commitment.

\section{Conclusion}

In this paper, I've provided a compositional treatment of rising imperatives in terms of the discourse effect of utterances of imperatives, and the discourse effect of utterances accompanied by the $\mathrm{L}^{*} \mathrm{H}-\mathrm{H} \%$ tune. With respect to the former, I've argued that utterances of imperatives perform much the same discourse move as that which Farkas \& Bruce (2010) define for assertions-where assertions update a doxastically-interpreted context, imperatives update a teleologically-interpreted context. With respect to the latter, I've adopted Truckenbrodt's (2006) independently motivated proposal that (steeply, monotonically) rising intonation calls off speaker commitment, and argued that this proposal accounts for the behavior of rising imperatives.

What results is a worldview in which rising imperatives are conventionally weak, withholding speaker commitment, and not just pragmatically weak, like 'offer' and 'request' uses of falling imperatives, in much the same way as rising declaratives are conventionally weaker than falling declaratives, irrespective of variation in the illocutionary interpretation of falling declaratives (see e.g. Gunlogson 2001; Malamud \& Stephenson 2015; Farkas \& Roelofsen 2017; Jeong 2018).

\section{References}

Bolinger, Dwight. 1989. Intonation and its uses: Melody in grammar and discourse. Stanford University Press.

13 See Portner (2018b) for a detailed discussion for the relationship between sentence mood (i.e. declarative, imperative) and verbal mood (i.e. indicative, subjunctive). 
Charlow, Nate. 2014. Logic and semantics for imperatives. Journal of Philosophical Logic 43(4). 617-664.

Condoravdi, Cleo \& Sven Lauer. 2012. Imperatives: meaning and illocutionary force. In Christopher Piñón (ed.), Empirical issues in syntax and semantics 9, 37-58.

Condoravdi, Cleo \& Sven Lauer. 2016. Anakastic conditionals are just conditionals. Semantics and Pragmatics doi:10.3765/sp.9.8.

Condoravdi, Cleo \& Sven Lauer. 2017. Conditional imperatives and endorsement. In A. Lamont \& K. Tetzloff (eds.), NELS 47, vol. 1, 185-204.

Farkas, Donka. 2011. Polarity particles in english and romanian. In J. Herschensohn (ed.), Romance Linguistics 2010, John Benjamins.

Farkas, Donka \& Kim Bruce. 2010. On reacting to assertions and polar questions. Journal of Semantics 27(1). 81-118.

Farkas, Donka \& Floris Roelofsen. 2017. Division of labor in the interpretation of declaratives and interrogatives. Journal of Semantics doi:10.1093/jos/ffw012.

Fitzpatrick, Justin. 2006. Deletion through movement. Natural Language and Linguistic Theory 24(2). 399-431.

Gunlogson, Christine. 2001. True to form: Rising and falling declaratives as questions in English: University of California, Santa Cruz PhD dissertation.

Jeong, Sunwoo. 2018. Intonation and sentence type conventions: Two types of rising declaratives. Journal of Semantics doi:10.1093/jos/ffy001.

Kaufmann, Magdalena. 2012a. Interpreting imperatives. Dordrecht: Springer Netherlands.

Kaufmann, Magdalena. 2012b. The modal operator theory of imperatives: Revisiting assets and drawbacks. Lecture notes from 'Topics in Modality' seminar, MIT.

Kaufmann, Magdalena. 2016. Fine-tuning natural language imperatives. Journal of Logic and Computation doi:10.1093/logcom/exw009.

Keough, Megan, Elise McClay, Molly Babel \& Lisa Matthewson. 2016. Intonational qualities of strong and weak imperatives. Poster presented at LabPhon15.

Malamud, Sophia \& Tamina Stephenson. 2015. Three ways to avoid commitments: Declarative force modifiers in the conversational scoreboard. Journal of Semantics 32(2). 275-311.

Merchant, Jason. 2004. Fragments and ellipsis. Linguistics and Philosophy 27(6). 661-738.

Portner, Paul. 2004. The semantics of imperatives within a theory of clause types. In Robert B. Young (ed.), SALT 14, 235-252. Evanston, IL: Northwestern University.

Portner, Paul. 2007. Imperatives and modals. Natural Language Semantics 15(4). 351-383. 
Rising imperatives

Portner, Paul. 2018a. Commitment to priorities. In Daniel Fogal, Daniel Harris \& Matt Moss (eds.), New work on speech acts, 296-316. Oxford University Press. Portner, Paul. 2018b. Mood. Oxford University Press.

Roberts, Craige. 1996. Information structure in discourse. In J.H. Yoon \& A. Kathol (eds.), Osu working papers in linguistics 49: Papers in semantics, 1-53. Ohio State University.

Rudin, Deniz. 2018. Rising above commitment: University of California, Santa Cruz PhD dissertation.

Schmerling, Susan. 1982. How imperatives are special, and how they aren't. In R. Schneider, K. Tuit \& R. Chametsky (eds.), The parasession on nondeclaratives, 202-218. Chicago Linguistic Society.

Stainton, Robert. 2005. In defense of non-sentential assertion. In Zoltan Szabo (ed.), Semantics versus pragmatics, 383-457. Oxford University Press.

Stalnaker, Robert. 1978. Assertion. In Peter Cole (ed.), Syntax and semantics 9, 315-32. Academic Press.

Starr, William. 2017. A preference semantics for imperatives. Manuscript, Cornell.

Truckenbrodt, Hubert. 2006. On the semantic motivation of syntactic verb movement to C in German. Theoretical Linguistics 32(3). 257-306.

Weir, Andrew. 2012. Left-edge deletion in english and subject omission in diaries. English Language and Linguistics 16(1). 105-129.

Weir, Andrew. 2016. The prosodic licensing of left-edge ellipsis and implications for clausal ellipsis. Invited presentation at Ellipsis and Prosody workshop, Leiden University.

Williamson, Timothy. 2000. Knowledge and its limits. Oxford University Press.

Zwicky, Arnold \& Geoffery Pullum. 1983. Deleting named morphemes. Lingua 59(2). 155-175.

Deniz Rudin

USC Department of Linguistics

3601 Watt Way

Grace Ford Salvatori 301E

Los Angeles, CA 90089

drudin@usc.edu 